Scientia Agricola

http://dx.doi.org/10.1590/1678-992X-2015-0472

\title{
Wood-associated fungi produce volatile organic compounds toxic to root-knot nematode
}

\author{
Lívia Pimenta $^{1}$, Maria Alves Ferreira ${ }^{1 *}$, Marcio Pozzobon Pedroso², Vicente Paulo Campos ${ }^{1}$
}

1Federal University of Lavras - Dept. of Plant Pathology, C.P. 3037 - 37200-000 - Lavras, MG - Brazil.

2Federal University of Lavras - Dept. of Chemistry, C.P.

3037 - 37200-000 - Lavras, MG - Brazil.

*Corresponding author <mariaferreira@dfp.ufla.br>

Edited by: Cláudio Marcelo Gonçalves de Oliveira

\begin{abstract}
Since volatiles do not leave residues in food and cause low toxicity to humans, they can act as a skeleton for new nematicidal molecules, once they have demonstrated activity against phytonematodes. The aim of this study was to evaluate the effect of volatile organic compounds (VOCs) released by wood-associated fungi on controling second-stage juveniles (J2) of Meloidogyne incognita. All 28 wood-associated fungi isolates produced VOCs which caused in excess of $76 \%$ immobility in exposed J2 of $M$. incognita. The fungus isolate VOCs also caused significant mortality compared to control when J2 were exposed to them. After $6 \mathrm{~h}$ of exposure, the fungus species Epicoccum nigrum and Schizophyllum commune produced VOCs that immobilized exposed J2 compounds, in relation to the control. When J2 were inoculated into tomato under greenhouse conditions, the $M$. incognita infectivity and reproduction were reduced by exposure to the VOCs. Volatiles produced by most of the fungi isolates and analyzed by gas chromatograph coupled to a mass spectrometer (CG-MS), included alcohols, esters, terpenes, and ketones. Certain compounds appeared only in $S$. commune or in E. nigrum suggesting their involvement in the high level of damage caused to nematode reproduction on tomato. Volatiles emitted by wood fungi demonstrated another mode of action of these microorganisms in nature. Keywords: Epicoccum nigrum, Schizophyllum commune, root nematodes, chromatography, control
\end{abstract}

Received December 09, 2015

Accepted August 15, 2016
Fungal isolates collected in natural forests are attractive candidates for the production of new molecules (nematicides, fungicides, or insecticides) which can control agricultural diseases (Parker et al., 1997). Investigation into the VOCs produced by wood-associated fungi may serve in the future development of commercial products taking advantage of their antimicrobial potential, low cost, low toxicity, and easy handling (Freire et al., 2012). Thus, we isolated woodassociated fungi, tested the toxicity of VOCs to secondstage juveniles (J2) of root-knot nematode $M$. incognita, assessed different exposure times of $\mathrm{J} 2$ to fungal VOCs, evaluated the infectivity of $\mathrm{J} 2$ of $M$. incognita exposed to fungal VOCs in tomato seedlings, and characterized the volatile molecules emitted by the best isolates by solid phase microextraction (SPME) and gas chromatography-mass spectrometry (GC-MS).

\section{Materials and Methods}

Ojaghian et al., 2012). In addition to toxicity to pathogens, VOCs can attract natural enemies and can act as an activation signal for resistance-related genes (Aharoni et al., 2003; Arimura et al., 2005; Kessler et al., 2006). The low toxicity of volatile molecules to humans opens up the possibility of success as a marketable molecule once they have proven their toxicity to pathogens. Studies detected that volatile molecules emitted by fungi cultures had nematicide and nematostatic effects on the Meloidogyne species (Riga et al., 2008; Freire et al., 2012). Other studies have shown nematicide and fungicidal effects of VOCs produced by plants, such as isothiocyanates (Lazzeri et al., 1993; Zasada and Ferris, 2003; Ojaghian et al., 2012).

\begin{abstract}
Isolation, preparation and maintenance of fungal isolates

We used 28 fungal isolates from different substrates (decaying trees and stumps) in forest fragments in Lavras, in the state of Minas Gerais, Brazil, geographic coordinates $21^{\circ} 13^{\prime} 39.1^{\prime \prime} \mathrm{S}, 4^{\circ} 58^{\prime} 06.3^{\prime \prime} \mathrm{W}$ at an altitude of $919 \mathrm{~m}$. These fungi were isolated by removing fragments from fruiting bodies or dead wood. The surface was sterilized in $70 \%$ alcohol with $5 \%$ hypochlorite for $30 \mathrm{~s}$. The excess hypochlorite was then eliminated with sterile water. After surface disinfection, the fragments were transferred to a Petri dish containing Potato Dex-
\end{abstract}


trose Agar (PDA) and incubated in a growth chamber with a $12 \mathrm{~h}$ photoperiod at a temperature of $25^{\circ} \mathrm{C}$ for 7 days. The grown fungi were transferred to new dishes containing PDA culture medium. After growth, the isolates were stored using three different media: test tubes containing PDA, $15 \%$ glycerol at $-80^{\circ} \mathrm{C}$, and Castellani's (Castellani, 1939) storage method at room temperature. Castellani's method was used in the assays and the other two methods were used for long period storage to avoid loss.

\section{Extraction and suspension of $\mathrm{J} 2$ of $M$. incognita}

Egg suspensions were obtained according to Hussey and Barker technique (1973) from pure populations of $M$. incognita on tomato plants multiplied and maintained in a greenhouse. The eggs were counted and then placed in a hatching chamber at $28{ }^{\circ} \mathrm{C}$. Only the J2, which hatched $48 \mathrm{~h}$ after assembling the chamber, were used in the experiment.

\section{Toxicity in vitro of VOCs emitted wood-associated fungi to $\mathrm{J} 2$ of $M$. incognita}

To select fungal isolates producing VOCs toxic to $M$. incognita, we used the technique promulgated by Barros et al. (2014) with modifications. Briefly, SUPELCO ${ }^{\circ}$ SPME bottles $80 \times 28 \mathrm{~mm}$ (internal volume $39 \mathrm{~mL}$ ) with threaded caps were internally coated with a layer of silicone which provides a tight seal. Each bottle received $15 \mathrm{~mL}$ of water-agar and $6 \mathrm{~mL}$ of PDA culture medium through the top. A sterile $1.5 \mathrm{~mL} \mathrm{mi-}$ crotube was dug into growth medium to an average height and the internal PDA medium was cultured with each wood fungus isolate. For this, two discs, $2 \mathrm{~mm}$ in diameter were taken from the edges of fungal colonies incubated for 7 days at $25{ }^{\circ} \mathrm{C}$ and a photoperiod of 12 $\mathrm{h}$. They were then transferred to the PDA medium adjacent and opposite to the microtube. The bottle was sealed with plastic film, and incubated for 6 days at $25{ }^{\circ} \mathrm{C}$ in the dark (Figure 1). Supelco bottles without fungal inoculation were used as control. Then, $1 \mathrm{~mL}$ of a suspension containing $100 \mathrm{~J} 2$ was injected into the inner microtube with a syringe. The hole left by the syringe was sealed with adhesive tape, and the flasks with J2 were incubated in a growth chamber with a $12 \mathrm{~h}$ photoperiod and temperature of $25^{\circ} \mathrm{C}$ for $24 \mathrm{~h}$. Then, the tubes were opened, and the J2 suspensions in the microtubes transferred to a polyethylene plate to measure the numbers of mobile and immobile J2. After $24 \mathrm{~h}$ in pure water, the number of dead J2 was quantified. The experiments were conducted in a completely randomized design with four replications. The experiments were repeated twice. For this, the treatments were organized in factorial comprising two factors (treatment $\times$ experiment).

\section{Isolate identification}

Morphological characters and molecular were used to identify the isolates selected for assays in vi-

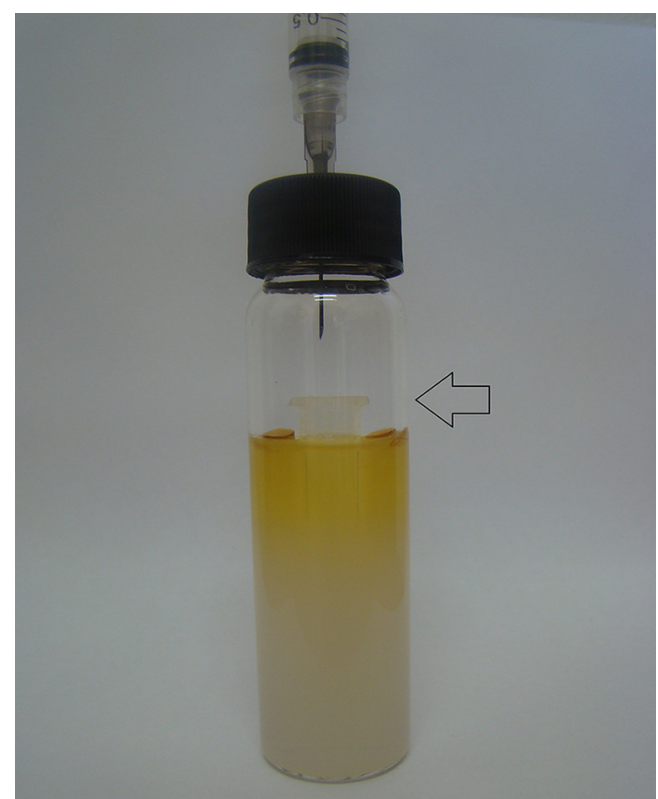

Figure 1 - Materials used during tests performed on volatile organic compounds (VOCs) emitted by isolates of wood-associated fungi and toxic to Meloidogyne incognita second-stage juveniles: Supelco ${ }^{\mathrm{TM}}$ SPME vial; screw top with silicone lining at the top; filled vial with culture medium; and a half-buried microtube showing the injection of the suspension of $M$. incognita second-stage juveniles into the buried microtube (arrow).

tro. DNA was extracted from the nine fungal isolates (PD8, PD10, PD12, PD13, PD14, PD21, PD22, PD27 and PD29). After transferring four mycelial disks to flasks containing $200 \mathrm{~mL}$ of liquid medium $(20 \mathrm{~g}$ malt extract $\mathrm{L}^{-1}$ ), mycelial masses were produced. The vials were stirred at $150 \mathrm{rpm}$ for 4 days at room temperature. Then, the mycelium was filtered, dried, and kept at $20{ }^{\circ} \mathrm{C}$ until extraction.

DNA extraction was performed according to the Wizard ${ }^{\circledR}$ Genomic DNA Purification Kit (Promega, Madison, USA). The region chosen for amplification was the ITS (internal transcribed spacer) using the GoTaq ${ }^{\circledR}$ Colorless Master Mix Kit (Promega ${ }^{\circledR}$ ), while purification was performed with the Wizard ${ }^{\varpi}$ PCR Preps DNA Purification System (Promega ${ }^{\circledR}$ ). The SeqAssem program (version 2007/2008) was used for editing the sequences. Gene sequences of the ITS region were compared with other sequences deposited in the GenBank (www.ncbi. nlm.nih.gov/Genbank) using the BLAST tool for similarity verification.

\section{Infectivity and reproduction of $\mathrm{J} 2$ of $M$. incognita} after exposure to VOCs

In this test we used the same nine fungal isolates identified from the previous study (PD8, PD10, PD12, PD13, PD14, PD21, PD22, PD27, and PD29). We also used tubes prepared with PDA as described in the previous test. One $\mathrm{mL}$ of a suspension containing $600 \mathrm{~J} 2$ of 
$M$. incognita was injected into the microtube that was inserted in the culture medium, which had been exposed to VOCs for $24 \mathrm{~h}$. Next, the J2 were removed from the microtube, dispersed in $4 \mathrm{~mL}$ of distilled water, and inoculated into 30 day old tomato seedlings in $75 \mathrm{~cm}^{3}$ cell seeding trays containing substrate. Three equidistant holes around the seedling were made using a glass rod ( $2 \mathrm{~mm}$ of diameter) within each cell. The inoculum suspension was performed with the aid of a $5 \mathrm{~mL}$ automatic pipette. The suspension was deposited in the holes. After inoculation, the trays were kept in a greenhouse where the inoculated seedlings were irrigated by manual spraying whenever necessary. The number of eggs and galls per root system were counted 30 days after inoculation. The experiments were conducted in a completely randomized design with five replications and repeated twice. For this, the treaments were organized in factorial comprising two factors (treatment $\times$ experiment).

\section{Toxicity of VOCs to J2 of $M$. incognita for different exposure time periods}

Among the fungal isolates emitting VOCs that caused mortality, four of them, identified as Epicoccum nigrum (PD8) and Schizophyllum commune (PD13, PD21, and PD29), were selected to test the sensitivity of $M$. incognita J2 to VOC exposure over different time periods. We prepared SUPELCO tubes with culture medium as described previously to receive the selected isolates. The tubes were sealed and incubated in a growth chamber with a $12 \mathrm{~h}$ photoperiod and temperature of $25^{\circ} \mathrm{C}$ for 6 days for the accumulation of VOCs. Then, $1 \mathrm{~mL}$ of a suspension of $100 \mathrm{~J} 2$ of $M$. incognita was injected into the microtube and left at $25^{\circ} \mathrm{C}$ for $0.5,3,6,12$, and 24 $\mathrm{h}$. At the end of each exposure period, the tubes were opened, and the J2 suspension contained in the microtubes were transferred to an ELISA plate to count the number of mobile and immobile J2. The experiments were conducted in a completely randomized design with four replications and were repeated twice. For this, the treatments were organized in factorial comprising three factors (treatment $\times$ time $\times$ experiment).

Identification of VOCs emitted by fungi by solid phase microextraction coupled to gas chromatography-mass spectrometry

PD8, PD13, PD21, and PD29 isolates were selected for VOCs identification. PD13 and PD21 were added to the analysis for comparison with PD29 because they belong to the same fungal species, $S$. commune. We used solid phase micro extraction (SPME) in the headspace mode (Arthur and Pawliszyn, 1990) with the following parameters: fiber DVB/CAR/PDMS (Divinylbenzene, Carboxen, and Polydimethylsiloxane), extraction temperature of $55{ }^{\circ} \mathrm{C}$, sample stirring at $250 \mathrm{rpm}$, extraction time of $35 \mathrm{~min}$ and desorption time in the GC injector of $2 \mathrm{~min}$. For separation and identification, we used a spectrometer (Shimadzu QP-2010 plus GC-MS), equipped with an auto injector, and an HP-5 column (5\% phenyl-95\% dimethylsiloxane) with dimensions $30 \mathrm{~m} \times 0.25 \mathrm{~mm} \times 0.25 \mu \mathrm{m}$. The injector temperature was $250{ }^{\circ} \mathrm{C}$, the interface temperature $240{ }^{\circ} \mathrm{C}$ and the ion source temperature $200{ }^{\circ} \mathrm{C}$. The injector was operated in splitless or split mode 1:4, according to the peak intensity in the samples. The carrier gas was He 5.0

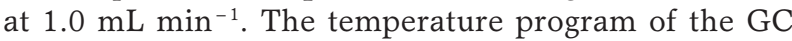
oven was as follows: an increase from $40^{\circ} \mathrm{C}$ to $160{ }^{\circ} \mathrm{C}$ at $3{ }^{\circ} \mathrm{C} \mathrm{min}$ min $^{-1}$ and then an increase to $240{ }^{\circ} \mathrm{C}$ at $10^{\circ} \mathrm{C}$ $\mathrm{min}^{-1}$. For the identification of the VOCs in the samples, we extracted the mass spectra of each peak in the chromatogram using the Automated Mass Spectral Deconvolution and Identification System (AMDIS) v.2.63 software. The identification of VOCs was performed by comparing the peak mass spectra in samples with spectra in the NIST Mass Spectral Library Search Program v. 1.7 (NIST, Washington, DC, USA) and by comparing the retention indices obtained experimentally (RI Exp.) with the retention rates in the literature (RI Lit.) (NIST, 2013; Adams, 2007). For comparing mass spectra, we considered only peaks with a spectra similarity greater than $80 \%$. The experimental retention indices were obtained by the injection of a homologous series of alkanes. Peaks were identified in the chromatograms only when mass spectra data agreed with the retention indices.

\section{Data analysis}

We used the Sisvar software program (version 5.3) for data analysis and performed analysis of variance (ANOVA). The averages of each treatment were grouped and differentiated by the Scott and Knott (1974) test $(p<0.05)$. For the analysis of the data related to exposure time, the regression models were adjusted, and the best model was selected based on $\mathrm{R}^{2}$ and error.

\section{Results}

\section{Meloidogyne incognita toxicity of VOCs emitted by wood-associated fungi}

In the immobility experiment, differences were observed $(p=0.046)$ in the interaction treatment $\times$ experiment. VOCs emitted by all 28 fungal isolates caused a significant reduction in mobility of $M$. incognita J2 ranging between 77 and $100 \%$ compared to control $(p \leq 0.05)$ (Table 1). Considering the two experiments, the isolates PD10, PD15, PD16, PD17, PD19, PD20, PD22, PD23, PD24, PD25, PD26, PD27, PD28, PD29 and PD32, showed high values of immobility compared with other treatments. In the first experiment, three groups were defined. The first group contained 27 isolates (PD1, PD2, PD4, PD5, PD8, PD10, PD12, PD13, PD14, PD15, PD16, PD17, PD18, PD19, PD20, PD21, PD22, PD23, PD24, PD25, PD26, PD27, PD28, PD29, PD30, PD31 and PD32) and caused immobility ranging between 93 and $100 \%$. The second group contained only one isolate (PD9) causing $77 \%$ immobil- 
Table 1 - Percentage of immobility and dead second stage juveniles (J2) of Meloidogyne incognita after exposure to volatile organic compounds of different isolates of wood associated fungi. Means followed by the same letter do not differ by the Scott and Knott test $(p<0.05)$.

\begin{tabular}{|c|c|c|c|c|}
\hline \multirow{2}{*}{ Treatment } & \multicolumn{2}{|c|}{ Exp. 1} & \multicolumn{2}{|c|}{ Exp. 2} \\
\hline & Immobility & Mortality & Immobility & Mortality \\
\hline Control & 18 & $\Delta c$ & $3 r$ & $3 \mathrm{~h}$ \\
\hline PD1 & $99 a$ & $8 c$ & $89 b$ & $17 \mathrm{a}$ \\
\hline PD2 & 99 a & $8 c$ & $94 \mathrm{~b}$ & $19 a$ \\
\hline PD4 & $100 \mathrm{a}$ & $38 \mathrm{a}$ & $93 \mathrm{~b}$ & $20 \mathrm{a}$ \\
\hline PD5 & $97 a$ & $27 \mathrm{~b}$ & $94 \mathrm{~b}$ & $13 a$ \\
\hline PD8 & $100 \mathrm{a}$ & $38 \mathrm{a}$ & $94 \mathrm{~b}$ & $28 \mathrm{a}$ \\
\hline PD9 & $77 b$ & $22 b$ & $95 a$ & $18 \mathrm{a}$ \\
\hline PD10 & $99 \mathrm{a}$ & $36 a$ & $100 \mathrm{a}$ & $25 \mathrm{a}$ \\
\hline PD12 & 93 a & $25 b$ & $91 \mathrm{~b}$ & $19 \mathrm{a}$ \\
\hline PD13 & $100 \mathrm{a}$ & $37 a$ & $92 b$ & $32 \mathrm{a}$ \\
\hline PD14 & $100 \mathrm{a}$ & $6 c$ & $90 \mathrm{~b}$ & $12 \mathrm{~b}$ \\
\hline PD15 & $98 \mathrm{a}$ & $7 c$ & $100 \mathrm{a}$ & $17 \mathrm{a}$ \\
\hline PD16 & $99 \mathrm{a}$ & $38 \mathrm{a}$ & $100 \mathrm{a}$ & $22 \mathrm{a}$ \\
\hline PD17 & $100 \mathrm{a}$ & $37 \mathrm{a}$ & 99 a & $18 \mathrm{a}$ \\
\hline PD18 & $100 \mathrm{a}$ & $30 \mathrm{~b}$ & $81 \mathrm{~b}$ & $13 a$ \\
\hline PD19 & $99 a$ & $38 a$ & $98 a$ & $7 \mathrm{~b}$ \\
\hline PD20 & $98 a$ & $18 \mathrm{c}$ & 99 a & $5 b$ \\
\hline PD21 & 99 a & $25 b$ & $95 \mathrm{~b}$ & $17 \mathrm{a}$ \\
\hline PD22 & 99 a & $38 \mathrm{a}$ & 99 a & $14 \mathrm{a}$ \\
\hline PD23 & $100 \mathrm{a}$ & $25 \mathrm{~b}$ & $98 a$ & $3 b$ \\
\hline PD24 & 99 a & $9 \mathrm{c}$ & 99 a & $6 \mathrm{~b}$ \\
\hline PD25 & $100 \mathrm{a}$ & $14 \mathrm{c}$ & $96 a$ & $4 \mathrm{~b}$ \\
\hline PD26 & $100 \mathrm{a}$ & $11 \mathrm{~b}$ & $100 \mathrm{a}$ & $6 \mathrm{~b}$ \\
\hline PD27 & $100 \mathrm{a}$ & $25 \mathrm{~b}$ & $100 \mathrm{a}$ & $15 \mathrm{a}$ \\
\hline PD28 & 99 a & $5 c$ & 99 a & $5 b$ \\
\hline PD29 & $100 \mathrm{a}$ & $9 c$ & $100 \mathrm{a}$ & $21 \mathrm{a}$ \\
\hline PD30 & $99 \mathrm{a}$ & $10 \mathrm{c}$ & $91 \mathrm{~b}$ & $8 b$ \\
\hline PD31 & $100 \mathrm{a}$ & $37 \mathrm{a}$ & $92 b$ & $8 b$ \\
\hline PD32 & $100 \mathrm{a}$ & $13 \mathrm{c}$ & 96 a & $6 \mathrm{~b}$ \\
\hline
\end{tabular}

ity. The third group contained only the control with $4 \%$ immobility (Table 1 ). In the second experiment, three groups were also defined. However the first group contained 16 isolates (PD9, PD10, PD15, PD16, PD17, PD19, PD20, PD22, PD23, PD24, PD25, PD26, PD27, PD28, PD29 and PD32) and caused immobility ranging between 95 and $100 \%$. The second group contained 12 isolates (PD1, PD2, PD4, PD5, PD8, PD12, PD13, PD14, PD18, PD21, PD30 and PD31) causing immobility ranging between 81 and $95 \%$. The third group contained only the control with $3 \%$ immobility (Table 1).

In the mortality experiment, differences were observed $(p=0.0001)$ in the interaction treatment $\times$ experiment. The mortality caused by fungal VOCs to $M$. incognita J2 ranged from 3 to $38 \%$, which was significantly greater than the control (Table 1). Considering the two experiments, the isolates PD4, PD8, PD10, PD13, PD16, PD17, and PD22 presented higher mortality rates compared to other treatments. In the first experiment, VOCs of isolates PD4, PD8, PD10, PD13, PD16, PD17, PD19, PD22, and PD21 caused the highest number of J2 deaths (35 to $38 \%$ ), followed by PD5, PD9, PD12, PD18, PD21, PD23, PD26, and PD27 which also caused significant mortality of $\mathrm{J} 2$ of $M$. incognita compared to the control. VOCs from the other isolates caused mortality similar to the control. In the second experiment the isolates PD1, PD2, PD4, PD5, PD8, PD10, PD12, PD13, PD15, PD16, PD17, PD18, PD21, PD22, PD27, and PD29 caused the highest number of J2 death (13 to $32 \%$ ). VOCs from the other isolates caused mortality similar to the control (Table 1).

\section{Isolate identification}

The amplification of the ITS region of the eight fungal isolates, PD29, PD21, PD13, PD14, PD10, PD8, PD22, and PD27 produced fragments of 335 to 611 base pairs (bp) (GenBank Accession numbers: KX668571 KX668578, respectively). Eight fungal isolates belonged to two classes of fungi, Ascomycetes and Basidiomycetes, according to their similarity in DNA to other sequences deposited in Genbank. The PD8 isolates as Epicoccum nigrum (100\%), PD13 (97 \%), PD21 (99 \%), and PD29 (100\%) as Schizophyllum commune were also identified as species levels and by morfological characters. PD10 as Pestalotiopsis sp. (100 \%); PD14 (100\%) as Phanaerochaete chrysosporium; PD22 (99 \%) as Nigrospora sp.; PD27 (98 \%) as Lasiodiplodia sp. were used as phylogenetic characters.

\section{Infectivity and reproduction of $\mathrm{J} 2$ of Meloidogyne} incognita after exposure to fungal VOCs

No difference was observed $(p=0.132)$ in the interaction treatment $\times$ experiment for infectivity of $M$. incognita in tomato, as indicated by the number of galls per root system. However, the number of galls per root system were highest when exposed to the fungal isolates PD8, PD14, PD21, PD27, and PD29 (Figure 2A). There was also no difference $(p=0.056)$ in the interaction treatment $\times$ experiment for the number of eggs. The number of eggs produced by adult females that developed after being exposed to VOCs of isolates PD8 and PD29 when in the J2 stage decreased by 67 and $81 \%$, respectively, compared to controls (Figure 2B).

\section{Toxicity of VOCs to J2 of $M$. incognita for different exposure periods}

No difference was observed $(p=0.641)$ in the interaction treatment $\times$ experiment $\times$ time. Exposure of $M$. incognita J2 to VOCs emitted by the fungal isolates PD8, PD13, PD21, and PD29 resulted in different percentages of $\mathrm{J} 2$ immobility over $24 \mathrm{~h}$ of exposure. For example, $50 \%$ immobility was reached at different times according to the different fungal isolates used: PD8 in $14 \mathrm{~h}, \mathrm{PD} 13$ in $12 \mathrm{~h}, \mathrm{PD} 21$ in $13 \mathrm{~h}$, and PD29 in $7 \mathrm{~h}$. Additionally, VOCs emitted by PD29 caused greater immobility compared to the other isolates, with a significant immobility increase after $6 \mathrm{~h}$ of exposure (Figure 3). 

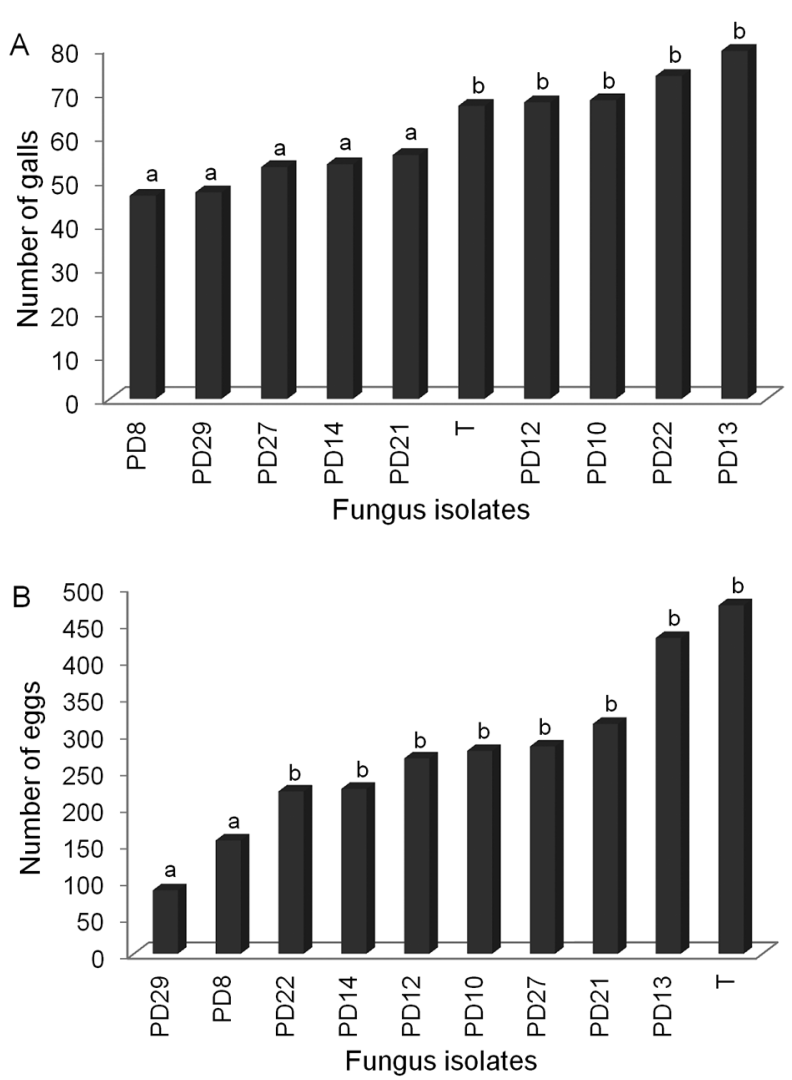

Figure 2 - Infectivity (A) and Reproduction (B) of Meloidogyne incognita in tomato inoculated with eggs exposed to volatile organic compounds emitted from different isolates of woodassociated fungi. Means followed by the same letter do not differ by the Scott and Knott test $(p<0.05) ; T=$ control.

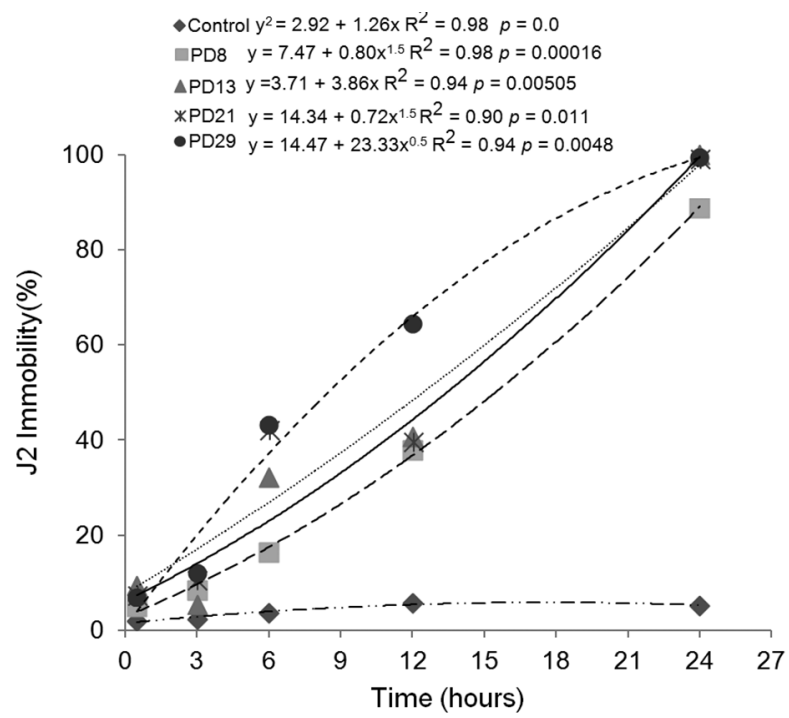

Figure 3 - Percentage of immobility of second stage juvenile (J2) of Meloidogyne incognita resulted from different time exposure to volatile compounds emitted by PD8, PD13, PD21 and PD29 isolates of wood- associated fungi.
Identification of fungal VOCs by solid phase microextraction coupled to gas chromatography-mass spectrometry

The VOCs produced by PD8 and PD29 samples were correctly identified and were different from those produced by the control (culture medium). Table 2 presents the identities of peaks numbered for each fungal species. Peaks were identified in chromatograms only when mass spectral data and retention indices were in agreement.

In general, the analysis by SPME-GC-MS of volatiles emitted by fungi PD8 (E. nigrum) and PD13, PD21, and PD29 (S. commune) showed the presence of 8, 9, 12, and 14 compounds grouped into the following classes: alcohols, terpenes, esters, and ketones, respectively. The compounds methanethiol, ethyl 2-methylbutanol and 3-methylbutanol appeared only in the chromatogram of PD29 (Table 2).

Table 2 - Identified volatile organic compounds emitted by woodassociated fungi by SPME-GC-MS.

\begin{tabular}{|c|c|c|c|c|c|c|c|}
\hline \# Compounds & RI Exp. ${ }^{1}$ & RI Lit. ${ }^{2}$ & ${ }^{2}$ Match $(\%)^{3}$ & PD8 & PD13 & PD21 & PD29 \\
\hline \multicolumn{8}{|l|}{ Alcohols } \\
\hline methanethiol & $x \mathrm{xx}$ & $x x x$ & 97 & & & & $x$ \\
\hline Ethanol & $x x x$ & $x x x$ & 97 & $\mathrm{x}$ & $\mathrm{x}$ & $x$ & $x$ \\
\hline $\begin{array}{l}\text { 2-methyl-pro- } \\
\text { panol }\end{array}$ & 623 & 622 & 88 & $\mathrm{x}$ & $x$ & $\mathrm{x}$ & $x$ \\
\hline 3-methyl-butanol & 730 & 734 & 95 & $\mathrm{x}$ & $x$ & $x$ & $x$ \\
\hline 2-methyl-butanol & 734 & 738 & 87 & $\mathrm{x}$ & $\mathrm{x}$ & $x$ & $\mathrm{x}$ \\
\hline $\begin{array}{l}\text { 6- methyl } \\
\text {-5-hepten-2-ol }\end{array}$ & 995 & 992 & 91 & $\mathrm{x}$ & & & \\
\hline \multicolumn{8}{|l|}{ Esters } \\
\hline ethylacetate & 615 & 615 & 94 & & $\mathrm{x}$ & $x$ & $x$ \\
\hline $\begin{array}{l}\text { methylthioac- } \\
\text { etate }\end{array}$ & 702 & 701 & 90 & & & $x$ & $x$ \\
\hline $\begin{array}{l}\text { ethyl 2-methyl- } \\
\text { propionate }\end{array}$ & 755 & 757 & 91 & & $\mathrm{x}$ & $x$ & \\
\hline $\begin{array}{l}\text { methyl 2-methyl- } \\
\text { butanoate }\end{array}$ & 775 & 778 & 86 & & $x$ & $\mathrm{x}$ & \\
\hline $\begin{array}{l}\text { ethyl 2-methylbu- } \\
\text { tanoate }\end{array}$ & 842 & 848 & 94 & & $\mathrm{x}$ & $x$ & $\mathrm{x}$ \\
\hline $\begin{array}{l}\text { 3-methyl-butanol } \\
\text { acetate }\end{array}$ & 877 & 875 & 94 & & & & $x$ \\
\hline $\begin{array}{l}\text { 2-methyl-butanol } \\
\text { acetate }\end{array}$ & 879 & 880 & 94 & & & & $x$ \\
\hline \multicolumn{8}{|l|}{ Terpenes } \\
\hline alpha-myrcene & 991 & 991 & 85 & $\mathrm{x}$ & & & \\
\hline methylnerolate & 1282 & 1279 & 86 & $\mathrm{x}$ & & & \\
\hline $\begin{array}{l}\text { gamma-himach- } \\
\text { alene }\end{array}$ & 1485 & 1476 & 90 & & $\mathrm{x}$ & $\mathrm{x}$ & $x$ \\
\hline alpha-curcumene & 1488 & 1483 & 94 & & $\mathrm{x}$ & $\mathrm{x}$ & $x$ \\
\hline $\begin{array}{l}\text { gamma-bisab- } \\
\text { olene }\end{array}$ & 1514 & 1515 & 83 & & $x$ & $x$ & $\mathrm{x}$ \\
\hline alpha-bisabolol & 1681 & 1683 & 83 & & $\mathrm{x}$ & $x$ & $x$ \\
\hline \multicolumn{8}{|l|}{ Ketones } \\
\hline $\begin{array}{l}\text { 6-methyl-5-hep- } \\
\text { ten-2-one }\end{array}$ & 988 & 985 & 84 & $\mathrm{x}$ & & & \\
\hline
\end{tabular}

${ }^{1} \mathrm{RI}$ Exp. $=$ Experimental retention index; ${ }^{2} \mathrm{RI}$ Lit. $=$ Literature retention index (Adams, 2007; NIST, 2013); ${ }^{3}$ Match (\%) = similarity between library spectra and peak spectra; PD8, PD13, PD21, and PD29 = referred to fungus isolates. 


\section{Discussion}

Although the immobility of $\mathrm{J} 2$ of $M$. incognita caused by VOCs produced by wood-associated fungi had been high, the mortality was low, reaching a maximum of $38 \%$. These results proved the nematicide and nematostatic effects of VOCs produced by wood-associated fungi. However, much higher mortality levels of $M$. incognita caused by VOCs emitted by fungi isolated from coffee rhizosphere were demonstrated by Freire et al. (2012). The production of volatile emissions by E. nigrum, S. commune, P. chrysosporium, Nisgrospora sp., and Lasiodiplodia sp. toxic to nematodes have not yet been described; however, many other fungi species produce volatiles toxic to plant pathogenic nematode and to other plant pathogens (Campos et al., 2010; Huang et al., 2010).

The ascomycetes $M$. albus and Trichoderma spp. can produce a mixture of volatiles that effectively control the growth of a wide range of micro-organisms (Eziashi et al., 2006; Ezra and Strobel, 2003). Additionally, Schalchli et al. (2011) reported the efficiency of VOCs produced by the basidiomycete $S$. commune against the fungi Botrytis cinerea, F. oxysporum and Mucor miehei.

Nematode toxicity was expressed as early because of exposure time to the volatiles. The gradual and fast immobility of $M$. incognita J2 in the first hours of exposure to VOCs of wood-associated fungi and complete immobility after $24 \mathrm{~h}$ of exposure which were observed here are in agreement with data obtained by Gu et al. (2007). They reported a reduction in mobility in Bursaphelenchus xylophilus and Panagrellus redivivus between 1 and $12 \mathrm{~h}$ and total immobility of these nematodes within $24 \mathrm{~h}$ of exposure. Grimme et al. (2007) also found a reduction in the mobility of $\mathrm{J} 2$ of $M$. incognita for different times. Immobilization of 31,74 , and $100 \%$ occurred after 24 , 72 , and $168 \mathrm{~h}$ of exposure to VOCs emitted by the fungus $M$. albus, respectively. Differences in immobility per different exposure times of J2 to VOCs indicate the level of nematode sensitivity to the volatile molecule, which may lead to death or irreversible mobilization. This sensitivity was mainly detected when J2 were exposed to isolate PD29, which immobilized a greater number of nematodes in a shorter time compared to the other isolates. As different sources of volatiles cause mortality or immobility of nematodes, distinct molecules may have different modes of action on the nematode body.

Physiological damage to the phytonematode exposed to sources of volatiles may be evaluated in terms of plant infectivity and nematode reproduction. In this study nematode immobility retards the life cycle in a susceptible host and a reduction of $M$. incognita eggs will lead to decreases in population. Reduction in tomato infectivity (numbers of galls) by $M$. incognita J2 after exposure to the VOCs of $F$. oxysporum was demonstrated by Freire et al. (2012). Huang et al. (2010) also found a reduction in the number of galls and eggs of $M$. incognita after exposure to volatiles of Bacillus megaterium YFM3.25. Metabolites produced by B. megaterium also caused a significant reduction in the number of root galls and eggs of nematodes of $M$. exigua in a study by Oliveira et al. (2007). Riga et al. (2008) used a formulation of fungus $M$. albus mixed with soil in an airtight plastic container and found that populations of Pratylenchus allius, $P$. penetrans, $M$. chitwood and $M$. hapla were reduced by 85 to $100 \%$ in the roots, but only by 56 to $100 \%$ in the soil.

Micro-organisms and plants produce diversified volatile molecules (Faria et al., 2014; Barbosa et al., 2010; Barros et al., 2014; Freire et al., 2012; Gu et al., 2007). The same occurred with wood-associated fungi in this study which produce several molecules of alcohol, ester, terpenes, and ketones. Compounds such as methanethiol and methyl thioacetate, contain sulfur and may have some toxic effects because other sulfur compounds, such as isothiocyanates, nitriles, thiocyanates, and epinitriles, have been proven to be toxic to nematodes (Mayton et al., 1996). The fact that isolates of the same species can produce different compounds or the same compounds in different quantities may be related to genetic variability within species. Thus, different isolates of the same genus can produce different profiles of VOCs. For example, Karlshoj and Larsen (2005) analyzed the production profile of volatile compounds of 24 isolates of Penicillium spp. and found that Penicillium paneum had a unique profile of volatile metabolites compared to the $P$. roquefort $i$ and $P$. carneum species. However, differences in volatile production among isolates of the same species may also be related to the exposure time that each isolate requires to become immobilized or to cause mortality in the micro-organism.

In this study, we found similarities and differences in the production of VOCs by ascomycetes and basidiomycetes. Variation in the production of both classes of compounds has been reported in other studies. Buzzini et al. (2003) and Buzzini et al. (2005) assessed isolates of ascomycete and basidiomycetous yeasts and found volatile alcohols (amyl and isoamyl alcohol), aldehydes (2-methyl-2-hexenal and 2-isopropyl-5-methyl2-hexenal), and esters (isobutyl acetate, isoamyl acetate, 2-methylbutyl acetate, ethyl isovalerate, isoamylpropionate, and phenylmethyl). Basidiomycetous yeasts had a greater number of alcohol (isobutyl alcohol, amyl alcohol, and isoamyl alcohol) and ester compounds (ethyl acetate, ethylpropionate, n-propyl acetate, isobutyl acetate, n-propyl propionate, n-butyl acetate, isoamylacetate, amyl acetate, isoamylpropionate, amyl propionate, and 2-phenylmethyl acetate).

Several volatile compounds similar to those we found were identified in $S$. commune by Schalchli et al. (2011), including ethanol and $\beta$-bisabolol. These compounds are commonly found in plants (Lopes-Lutz et al., 2008 ) and in the essential oil of $S$. commune (Ziegenbein et al., 2006). Bisabolol is known for its anti-irritant, antiinflammatory, and antimicrobial properties (Zekovic et al., 1994). However, neither ethanol nor bisabolol were tested for toxicity to phytonematodes. 
The four VOCs produced by E. nigrum (PD8) and S. commune (PD29) (ethanol, 2-methyl-propanol, 3-methyl-butanol, and 2-methyl-butanol) are typical fungal compounds that have been detected in other studies to evaluate the effect of VOCs on nematodes (Fialho et al., 2010; Grimme et al., 2007). However, the compounds methanethiol, methylthioacetate, 3-methyl-butanol acetate and 2-methyl-butanol acetate were produced only by $S$. commune (PD29) (Table 1). Grimme et al. (2007) used an artificial mixture of volatiles produced by the fungus $M$. albus, including 3-methyl-1-butanol, 3-methyl-1-butanol acetate and some esters, and found that this mixture reduced the number of root galls by $M$. incognita in tomato plants in vivo. Fialho et al. (2010) reported that VOCs consisting of alcohols are mainly responsible for the bioactivity of Saccharomyces cerevisiae against the fungus Guignardia citricicarpa. According to the authors, an artificial mixture of VOCs with the compounds 3-methyl-1-butanol and 2-methyl-1-butanol was able to fully suppress the development of $G$. citricicarpa. Fialho et al. (2012) also performed fumigation on a substrate containing second-stage juveniles with a mixture of synthesized VOCs including the molecules cited above. The nematicide effect was over $30 \%$ with the lowest substrate concentration $\left(33.3 \mu \mathrm{L} \mathrm{g}^{-1}\right)$, and with 66.6 and $133.3 \mu \mathrm{L} \mathrm{g}^{-1}$ of the substrate, the nematode mortality was $100 \%$. The present study showed the importance of screening VOCs produced by woodassociated fungi to control nematodes. In the future investigations studies will be necessary, mainly on the molecules separately though also in a mixture to confirm the action mechanism of those molecules.

\section{Acknowledgments}

We wish to thank the Minas Gerais State Foundation for Research Support (FAPEMIG) (Project Agriculture Chamber (CAG) for research project (APQ)$01626 / 12$, the Chamber of exact sciences and materials (CEX)-APQ-04331-10), Coordination for the Improvement of Higher Level Personnel (CAPES) and the Brazilian National Council for Scientific and Technological Development (CNPq) for providing scholarships and financial support to implement this study.

\section{References}

Adams, R.P. 2007. Identification of Essential Oil Components by Gas Chromatography/Mass Spectrometry. Allured Publishing, Carol Stream, IL, USA.

Agência Nacional de Vigilância Sanitária [ANVISA]. 2012. Pesticide shaped pellet is banned from the Brazilian market = Agrotóxico em forma de chumbinho é banido do mercado Brasileiro. Available at: http://www.brasil.gov.br/noticias/ arquivos/2012/11/05/agrotoxico-em-forma-de-chumbinho-ebanido-do-mercado-brasileiro [Accessed July 10, 2013] (in Portuguese).
Aharoni, A.; Giri, A.P.; Deuerlein, S.; Griepink, F.; Kogel, W.J.D.E.; Verstappen, F.W.A.; Verhoeven, H.A.; Jongsma, M.A.; Schwab, W.; Bouwmeester, H.J. 2003. Terpenoid metabolism in wild-type and transgenic Arabidopsis plants. The Plant Cell 15: 2866-2884.

Arimura, G.; Kost, C.; Boland, W. 2005. Herbivore-induced, indirect plant defences. Biochimica et Biophysica Acta 1734: 91-111.

Arthur, C.L.; Pawliszyn, J. 1990. Solid-phase microextraction with thermal desorption using fused silica optical fibers. Analytical Chemistry 62: 2145-2148.

Barbosa, P.; Lima, A.S.; Vieira, P.; Dias, L.S.; Tinoco, M.T.; Barroso, J.G.; Pedro, L.G.; Figueiredo, A.C.; Mota, M. 2010. Nematicidal activity of essential oils and volatiles derived from Portuguese aromatic flora against the pinewood nematode Bursaphelenchus xylophilus. Journal of Nematology 42: 8-16.

Barros, A.F.; Campos, V.P.; Silva, J.C.P.; Pedroso, M.P.; Medeiros, F.H.V.; Pozza, E.A.; Reale, A.L. 2014. Nematicidal activity of volatile organic compounds emitted by Brassica juncea, Azadirachta indica, Canavalia ensiformis, Mucuna pruriens and Cajanus cajan against Meloidogyne incognita. Applied Soil Ecology 80: 34-43.

Buzzini, P.; Martini, A.; Cappelli, F.; Pagnoni, U.M.; Davoli, P. 2003. A study on volatile organic compounds (VOCs) produced by tropical ascomycetous yeasts. Antonie Van Leeuwenhoek 84: 301-311.

Buzzini, P.; Romano, S.; Turchetti, B.; Vaughan, A.; Pagnoni, U.M.; Davoli, P. 2005. Production of volatile organic sulfur compounds (VOCs) by basidiomycetous yeasts. FEMS Yeast Research 5: 379-385.

Campos, V.P.; Pinho, R.S.C.; Freire, E. 2010. Volatiles produced by interacting microorganisms potentially useful for the control of plant pathogens. Ciência e Agrotecnologia 34: 525-535.

Castellani, A. 1939. Viability of some pathogenic fungi in distilled water. Journal of Tropical Medicine and Hygiene 42: 225-226.

Chitwood, D.J. 2002. Phytochemical based strategies for nematode control. Annual Review of Phytopathology 40: 221-249.

Eziashi, E.I.; Uma, N.U.; Adekunle, A.A.; Airede, C.E. 2006. Effect of metabolites produced by Trichoderma species against Ceratocystis paradoxa in culture medium. African Journal of Biotechnology 5: 703-706.

Ezra, D.; Strobel, G.A. 2003. Effect of substrate on the bioactivity of volatile antimicrobials produced by Muscodor albus. Plant Science 165: 229-238.

Faria, J.M.S.; Sena, I.; Silva, V.I.; Ribeiro, B.; Barbosa, P.; Ascensão, L.; Bennett, R.N.; Mota, M.; Figueiredo, A.C. 2014. In vitro co-cultures of Pinus pinaster with Bursaphelenchus xylophilus: a biotechonological approach to study pine wilt disease. Planta 241: 1325-1336.

Fialho, M.B.; Toffano, L.; Pedroso, M.P.; Augusto, F.; Pascholati, S.F. 2010. Volatile organic compounds produced by Saccharomyces cerevisiae inhibit the in vitro development of Guignardia citricarpa, the causal agent of citrus black spot. World Journal of Microbiology and Biotechnology 26: 925-932.

Fialho, M.B.; Bessi, R.; Inomoto, M.M.; Pascholati, S.F. 2012. Nematicidal effect of volatile organic compounds (VOCs) on the plant-parasitic nematode Meloidogyne javanica. Summa Phytopathologica 38: 152-154. 
Freire, E.S.; Campos, V.P.; Pinho, R.S.C.; Oliveira, D.F.; Faria, M.R.; Pohlit, A.M.; Norberto, N.P.; Rezende, E.L.; Pfenning, L.H.; Silva, J.C.T. 2012. Volatile substances produced by Fusarium oxysporum from coffee rhizosphere and other microbes affect Meloidogyne incognita and Arthrobotrys conoides. Journal of Nematology 44: 321-328.

Grimme, E.; Zidack, N.K.; Sikora, R.A.; Strobel, G.A.; Jacobsen, B.J. 2007. Comparison of Muscodor albus volatiles with a biorational mixture for control of seedling diseases of sugar beet and root knot nematode on tomato. Plant Disease 91: 220225.

Gu, Y.Q.; Mo, M.H.; Zhou, J.P.; Zou, C.S.; Zhang, K.Q. 2007. Evaluation and identification of potential organic nematicidal volatiles from soil bacteria. Soil Biology and Biochemistry 39: 2567-2575.

Huang, Y.; Xu, C.K.; Ma, L.; Zhang, K.Q.; Duan, C.Q.; Mo, M.H. 2010. Characterisation of volatiles produced from Bacillus megaterium YFM3.25 and their nematicidal activity against Meloidogyne incognita. European Journal of Plant Pathology 126: 417-422.

Karlshoj, K.; Larsen, T.O. 2005. Differentiation of species from the Penicillium roqueforti group by volatile metabolite profiling. Journal of Agricultural and Food Chemistry 53: 708715.

Kessler, A.; Halitschke, R.; Diezel, C.; Baldwin, I.T. 2006. Priming of plant defense responses in nature by airborne signaling between Artemisia tridentata and Nicotiana attenuata. Acta Oecologica 148: 280-292.

Lazzeri, L.; Tacconi, R.; Palmieri, S. 1993. In vitro activity of some glucosinolates and their reaction products toward a population of the nematode Heterodera schachtii. Journal of Agricultural and Food Chemistry 41: 825-829.

Lopes-Lutz, D.; Alviano, D.S.; Alviano, C.S.; Kolodziejczyk, P.P. 2008. Screening of chemical composition, antimicrobial and antioxidant activities of Artemisia essential oils. Phytochemistry 69: $1732-1738$

Mayton H.S.; Claudia, O.; Vaughn, S.F.; Loria, R. 1996. Correlation of fungicidal activity of Brassica species with alil isotiocianato production in macerated leaf tissue. Phytopathology 86: 267271.
Neves, W.E.; Freitas, L.G.; Coutinho, M.M.; Parreira, D.F.; Ferraz, S.; Costa, M.D. 2007. Biofumigation of soil with species of Brassicaceae for the control of Meloidogyne javanica. Nematologia Brasileira 31: 195-201 (in Portuguese, with abstract in English).

National Institute of Standards and Technology [NIST]. 2013. NIST chemistry webbook = NIST livro de química na web. Available at: http://webbook.nist.gov/chemistry/ [Accessed Nov 05, 2013] (in Portuguese).

Ojaghian, M.R.; Jiang, H.; Xie, G.L.; Cui, Z.Q.; Zhang, Z.; Li, B. 2012. In vitro biofumigation of brassica tissues against potato stem rot caused by Sclerotinia sclerotiorum. Plant Pathology 28: 185-190.

Oliveira, D.F.; Campos, V.P.; Amaral, D.R.; Nunes, A.S.; Pantaleão, J.Á.; Cost, A.A. 2007. Selection of rhizobacteria able to produce metabolites active against Meloidogyne exigua. European Journal of Plant Pathology 119: 477-479.

Parker, S.; Cutler, H.; Jacyno, J.; Hill, R. 1997. Biological activity of 6-pentyl-2H-pyran-2-one and its analogs. Journal of Agricultural and Food Chemistry 45: 2774-2776.

Riga, E.; Lacey, L.A.; Guerra, N. 2008. Muscodor albus, a potential biocontrol agent against plant-parasitic nematodes of economically important vegetable crops in Washington State, USA. Biological Control 45: 380-385.

Schalchli, H.; Hormazabal, E.; Becerra, J.; Birkett, M.; Alvear, M.; Vidal, J.; Quiroz, A. 2011. Antifungal activity of volatile metabolites emitted by mycelial cultures of saprophytic fungi. Chemistry and Ecology 27: 503-513.

Scott, A.J.; Knott, M.A.A. 1974. Cluster analysis method for grouping means in the analysis of variance. Biometrics 30: 507512.

Zasada, I.A.; Ferris, H. 2003. Sensitivity of Meloidogyne javanica and Tylenchulus semipenetrans to Isothiocyanates in laboratory assays. Phytopathology 93: 747-750.

Zekovic, Z.; Pekic, B.; Lepojevic, Z.; Petrovic, L. 1994. Chromatography in our investigations of camomile (Matricaria chamomilla L.). Chromatographia 39: 587-443.

Ziegenbein, F.C.; Hanssen, H.P.; König, W.A. 2006. Chemical constituents of the essential oils of three wood-rotting fungi. Flavour and Fragrance Journal 21: 813-816. 